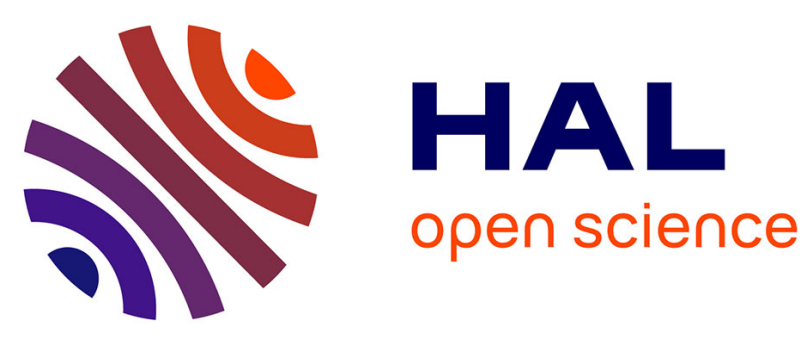

\title{
Detection of Moroccan coastal upwelling using sea surface chlorophyll concentration
}

\author{
Anass El Aouni, Khalid Minaoui, Ayoub Tamim, Khalid Daoudi, Hussein \\ Yahia, Abderrahman Atillah, Driss Aboutajdine
}

\section{- To cite this version:}

Anass El Aouni, Khalid Minaoui, Ayoub Tamim, Khalid Daoudi, Hussein Yahia, et al.. Detection of Moroccan coastal upwelling using sea surface chlorophyll concentration. 12th ACS/IEEE International Conference on Computer Systems and Applications AICCSA 2015, Nov 2015, Agadir, Morocco. 10.1109/AICCSA.2015.7507165 . hal-01360038

\section{HAL Id: hal-01360038 \\ https://hal.inria.fr/hal-01360038}

Submitted on 5 Sep 2016

HAL is a multi-disciplinary open access archive for the deposit and dissemination of scientific research documents, whether they are published or not. The documents may come from teaching and research institutions in France or abroad, or from public or private research centers.
L'archive ouverte pluridisciplinaire HAL, est destinée au dépôt et à la diffusion de documents scientifiques de niveau recherche, publiés ou non, émanant des établissements d'enseignement et de recherche français ou étrangers, des laboratoires publics ou privés. 


\title{
Detection of Moroccan coastal upwelling using sea surface chlorophyll concentration
}

\author{
Anass El Aouni ${ }^{1}$, Khalid Minaoui ${ }^{1}$, Ayoub Tamim ${ }^{1}$, Khalid Daoudi $^{2}$, Hussein Yahia ${ }^{2}$, Abderrahman Atillah $^{3}$, \\ Driss Aboutajdine ${ }^{1}$ \\ ${ }^{1}$ Mohammed V-Agdal University, LRIT Associated Unit to the CNRST-URAC n 29, Rabat, Morocco \\ ${ }^{2}$ INRIA Bordeaux Sud-Ouest (GEOSTAT team), Talence, France \\ ${ }^{3}$ Royal Centre of Remote Sensing (CRTS), Rabat, Morocco \\ anas.elaouni@gmail.com
}

\begin{abstract}
The aim of this work is to automatically identify and extract the upwelling area in the coastal ocean of Morocco using the satellite observation of chlorophyll concentration. The algorithm starts by the application of FCM algorithm for the purpose of finding regions of homogeneous concentration of the chlorophyll, resulting in c-partitioned labeled images. A regiongrowing algorithm is then used to filter out the noisy structures in the offshore waters not belonging to the upwelling regions. The proposed methodology has been validated by an oceanographer and tested over a database of 166 weekly Sea Surface chlorophyll data. The region of interst cover the southern part of Moroccan atlantic coast spanning from the years 2007 to 2012 .
\end{abstract}

Keywords: Upwelling, Satellite chlorophyll concentration, Fuzzy clustering algorithm, Region-growing.

\section{INTRODUCTION}

The coastal ocean of Morocco, located in the western boundary of the North Atlantic, is characterized by the presence of upwelling phenomenon. In fact, the Moroccan upwelling is evidenced at the surface by cold and nutrientrich waters near the coast in response to the intensification of northeasterly winds and Ekman transport along the continental shelf. The Moroccan coast is characterized by persistent and variable upwelling all around the year making it rich in fishery resources [13].

The upwelling process which result of high levels of primary productivity and fishery production, draws up cold water from deep, below the warmer surface. As the cooler water rises, it brings with it phytoplankton and nutrients necessary for life. Which attract mobile predators such as fishes, birds and marine mammals [5].

Chlorophyll concentration provides an estimate of the live phytoplankton biomass in the surface layer, which is an important part of the ocean's food chain because many animals feed on them [1]. Scientists use remote sensing data to measure how much phytoplankton are growing in the ocean by observing the color of the light reflected from the shallow depths of the water. Phytoplankton contain a photosynthetic pigment called chlorophyll that lends them a greenish color. When phytoplankton grow in large numbers they make the ocean appear green in colour.
The detection and monitoring of coastal upwelling using sea surface chlorophyll images is necessary for many applications. In particular, the Moderate Resolution Imaging Spectroradiometer sensor aboard the Terra and Aqua spacecraft, is frequently used to study and localise the upwelling boundaries between the greenish upwelling waters presenting the hight concentration chlorophyll near the coast and the lower concentration chlorophyll in the offshore direction.

Usually, the detection of upwelling regions has been made by a very time consuming process, which use color scale map for each image. In order to overcome these problems, it is necessary to develop an automatic tools for the precise detection of upwelling region from remote ocean color data.

In the literature several techniques and methods have been proposed in order to automatically detect the upwelling area using the satellite chlorophyll images. Some of them provide a good upwelling segmentations such as in [3][8][6]. The main drawbacks encountered in the preceding approach is that they requires a complex pre-processing step applied to the original image. More recently, the fuzzy C-means segmentation [15] was used to identify the upwelling area from SST images, by using 2 clusters based on the fact that the Morrocan upwelling in the southern part is characterized by very strong transition between cold water near the coast and warmer water in offshore.

In this paper, we are interested for the detection and extraction of the upwelling area in the coastal ocean of Morocco, which concentrates particles and forms privileged areas of high biological activity as pointed out by Bakun [2]. To achieve this goal, we follow the same philosophy as in [13] but we chose a dynamic number of cluster depending on the spatial distribution and the intensity of the chlorophyll.

The paper is organized as follows, in section 2 we introduce the database and the geographic area of interest used in this study. Section 3 describes an overview of the proposed methodology. Section 4 and Section 5 present respectively the upwelling detection and upwelling extraction steps of our methodology. At the final we highlights the results and the validation of the algorithm. Concluding remarks and future works are in section 7 . 


\section{REGION OF INTERSET AND DATASETS}

MODIS-T chlorophyll data were extracted from the Physical Oceanography Distributed Active Archive Center (PODAAC $)^{\dagger}$ with spatial resolution of $4 \times 4 \mathrm{~km}$, covering the southern part of Moroccan Atlantic coast spans from $20^{\circ} 380-$ $28^{\circ} 270 \mathrm{~N}$ and $11^{\circ} 170-23^{\circ} 00 \mathrm{~W}$. Each chlorophyll image is defined by $176 \times 176$ pixels, and each pixel represent milligrams of chlorophyll per cubic meter of seawater.

For the purpose of removing chlorophyll images contain large artifacts and heavy cloud, only chlorophyll images having more than $65 \%$ of valid information in the area between the coast and $200 \mathrm{~km}$ offshore were kept [10].

166 8-day MODIS-T CHL images are used to provide a coarse segmentation of upwelling areas, covering the years 2007 to 2012. the weekly synthetic data is chosen as a compromise between the variability of the CHL and the necessity to provide a continuous spatio-temporal coverage. A color scale is applied to our database, in order to help the oceanographer, getting the best contrast definition for a good visualization of upwelling area. Fig. 1 shows two chlorophyll images selected from our database illustrating two upwelling scenarios encountered throughout this work.
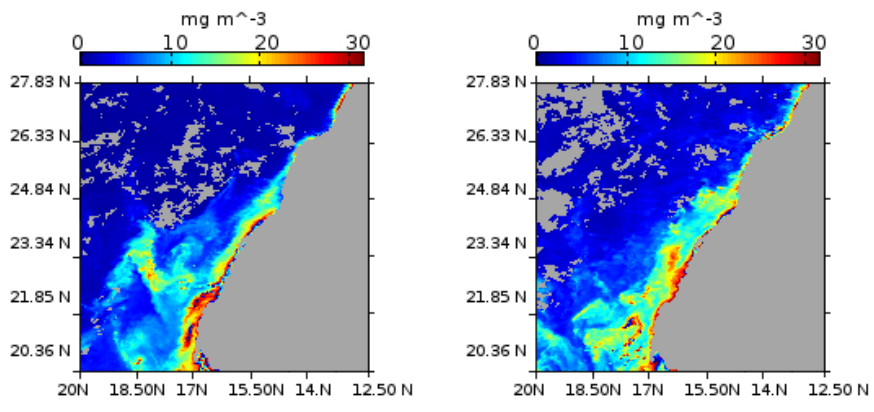

Fig. 1: Chlorophyll images obtained respectively on 2007-1029 and 2009-02-02, showing two different upwelling scenarios.

\section{OVERVIEW OF THE METHODOLOGY}

The proposed methodology that detect and localize the upwelling regions in Chlorophyll images can be summarized as follow :

- Upwelling detection step, the FCM algorithm is apllied for each chlorophyll image to provide a first segmentation of upwelling areas.

- Upwelling extraction step, in this step we apply the Region-growing algorithm, to remove the noisy structures not belonging upwelling regions from the first step output.

\section{UPWELLING DETECTION METHODOLOGY}

\section{A. Fuzzy clustering algorithm}

As a first step of the proposed methodology, a fuzzy clustering algorithm is applied to each chlorophyll images to

\footnotetext{
${ }^{\dagger} \mathrm{ftp} / / /$ podaac.jpl.nasa.gov
}

provide labeled clusters sharing the same statical properties. Each chlorophyll image is converted into a feature vector $X=\left\{x_{1}, x_{2}, \ldots, x_{n}\right\}$ of $n$ pixels, and the FCM algorithm is applied to that vector with a number of clusters varyring from $c_{\min }=2$ to $c_{\max }=4$, depending on the chlorophyll concentration and its spatial distribution as shown in the Fig.1 where the upwelling present two different scenarios about its intensity and extension.

The FCM algorithm is applied to minimize an objective function called c-means functional:

$$
J_{m}(X ; U, V)=\Sigma_{k=1}^{n} \Sigma_{i=1}^{c}\left(\mu_{i k}\right)^{m}\left\|x_{k}-v_{i}\right\|^{2}
$$

where $n$ is the length of the vector $X$ presenting pixels of a given chlorophyll image. $V=\left\{v_{1}, v_{2}, \ldots, v_{n}\right\}$ vector of cluster prototypes and $U=\left[\mu_{i k}\right]$ is the fuzzy partition matrix which presents the degree of belonging for each pixel $x_{k}$ to a given cluster $c_{i}$. The weighting exponent $m$ controls the fuzziness of membership values, which vary from $[1, \infty[$. An increase of $m$ lead to an increase of fuzziness partitions. In our work, we set this parameter to 2 .

The objective function (1) can be seen as a measure of the total variance of $x_{k}$ from $v_{i}$. The minimization of the objective function (1) represents a nonlinear optimization problem that can be solved by using respectively the following cluster centroids and membership functions :

$$
\begin{gathered}
v_{i}=\frac{\sum_{k=1}^{n}\left(\mu_{i k}^{m}\right) x_{k}}{\sum_{k=1}^{n}\left(\mu_{i k}^{m}\right)}, 1 \leq i \leq c \\
\mu_{i k}=\frac{1}{\sum_{j=1}^{c}\left(\frac{\left\|x_{k}-v_{i}\right\|}{\left\|x_{k}-v_{j}\right\|}\right)^{\frac{2}{(m-1)}}}, 1 \leq i \leq c, 1 \leq k \leq n
\end{gathered}
$$

The goal here is to iteratively improve a sequence of sets of fuzzy clusters through those equations until no further improvement is possible for the objective function.

\section{B. Optimal number of clusters}

In the FCM algorithm, the number of clusters is rarely known apriori and it's must be chosen with great care in order to have the optimal number of classes. Several approaches have been proposed to automatically determinate the number of clusters which better fits the data [7], which can be done by using validity indices for several values of $c$ and then evaluate the goodness of the obtained c-partition, which can be very time consuming for large datasets. Also depending on the nature of the datasets that present spatial information, which can be the main limitations of these indices.

In CUEA (Coastal upwelling ecosystems analysis) filed studies the spatial distributions of surface properties suggested that plankton communties respond to upwelling of new nutrients after time of few days, which led to the hypothesis that the upwelling process could be conceptually described as four sequential stages [7]. In the first stage, newly upwelled waters arrived at the surface close to the coastal boundry. As the recently upwelled waters flowed offshore in stage 2 the phytoplankton biomass increased. Stage 3 corresponds to the 
maximum phytoplantkon, as the upwelled waters continued to age. Stage 4 waters were found furthest offshore where the nutrient is depleted.

For that raison and due to the nature of the chlorophyll data that present high difference between the maximum and minimum values, the number of clusters is calculated as follow.

According to [14] the upwelling extension is spatially variable all around the year with maximum values of $250 \mathrm{~km}$. So that for each chlorophyll image 4 clusters of centers $\max$, $\frac{2 \times(\max -\min )}{3}, \frac{\max -\min }{3}$ and $\min$ were extracted from the region between the coastline and $250 \mathrm{~km}$ faraway, presenting different chlorophyll concentration during one upwelling cycle. Based on the fact that the upwelling region is characterized by a high chlorophyll concentration waters compared to the offshore waters. The algorithm start by number of 1 cluster presenting the upwelling areas, and increases it whenever the number of pixels presenting the cluster of highest value as center is less than $70 \%$ as described by the algorithm below.

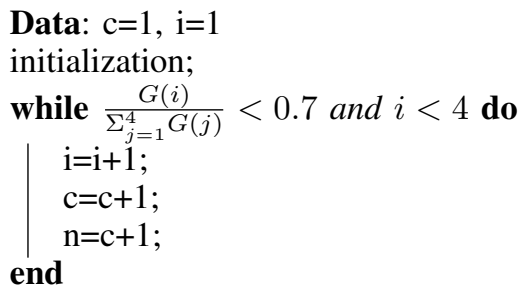

Algorithm 1: Optimal number of clusters

where the vector $G\left\{g_{1}, g_{2}, g_{3}, g_{4}\right\}$ present the number of pixels for centers $\max , \frac{2(\max -\min )}{3}, \frac{\max -\min }{3}$ and $\min$ respectively. $c$ is the number of clusters presenting the upwelling ares. $n$ is the input parameter of the FCM algorithm presenting the number of clusters.

Once the labeled image is generated using the fuzzy clustering algorithm with the optimal number of clusters $n$, the upwelling area is defined and labeled as the c highest clusters.

Fig. 2 shows the binary image result after the upwelling detection methodology. The white region on the binary images corresponds to upwelling area, whereas the black pixels correspond to offshore waters non affected by the coastal upwelling.
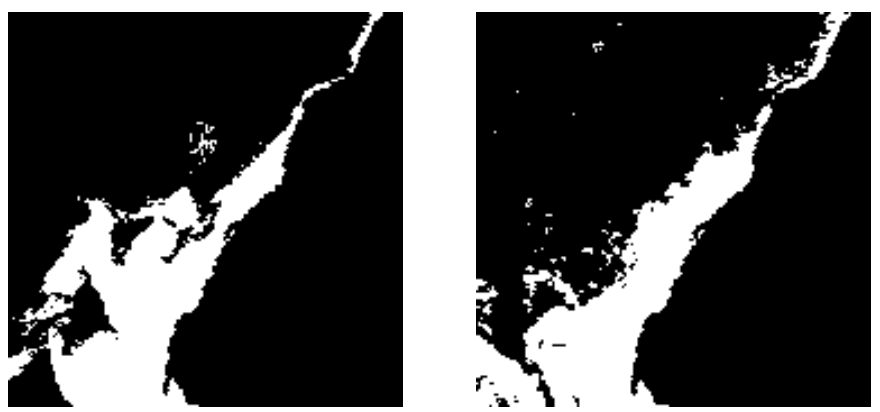

Fig. 2: Binary image result after the upwelling detection step for the two chlorophyll images of the Fig. 1

\section{UPWELLING EXTRACTION}

In addition to the Upwelling area, The first step's output include some additional noise structures faraway from the coast, not belonging to the upwelling region. For that reason and based on the fact that all pixels pertaining to the upwelling must have connectivity with the coastline, a segmentation procedure is required consisting on the application of the Region-growing algorithm to remove those isolated pixels in the offshore direction.

The Region-growing algorithm is a simple region-based image segmentation method that examines neighboring pixels of initial seed points and determines whether the adjacent pixel should be added to the region [4][14]. This method aims at grouping a set of pixels according to homogeneity and adjacency criteria [11]. In this work, we have chosed 8connected neighborhood for the adjacency criteria. Since the output of the upwelling detection step present a binary image, the stop condition is the value 0 . Fig. 3 shows the results of the area opening algorithm applied to the binary images of Fig. 2, where remaining pixels in offshore waters have been removed. Fig, 4 shows the final segmentation achieved by the proposed methodology, where the upwelling areas are automatically contoured.
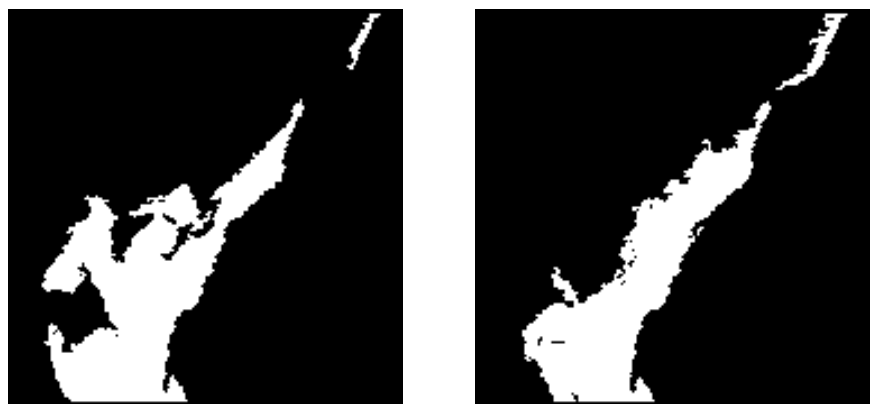

Fig. 3: Extracted upwelling areas using the region-growin algorithm over the two binary images of Fig. 2
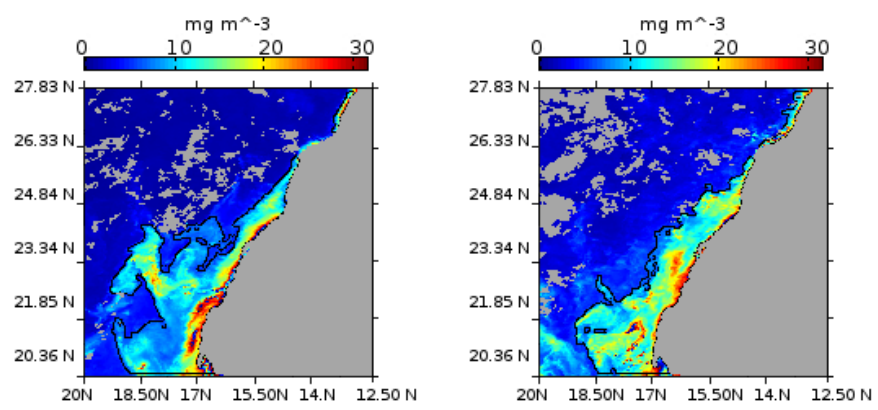

Fig. 4: Upwelling region automatically contoured using the proposed methodology over the chosed images in Fig. 1.

\section{RESULTS ANALYSIS ON THE WHOLE DATABASE}

Based on well-known fact that validation in the case of ocean data is often and truly performed by assessing the 
results by professional oceanographers [12] [6] [9], the performance ofthe proposed methodology has been validated by the oceanographer over the data set of 166 chl-a images, basing on the scientific and technical knowledge of the Moroccan atlantic coast.

Throughout this evaluation, we used 4 grades: "Poor", "Acceptable", "Good" and "excellent" to check if the proposed yield to a satisfactory identification of the upwelling area without over or missing-detection. "poor" is assigned when the upwelling areas is not well delimited by the algorithm, and "excellent" was assigned when the areas is well delimited. The results of the oceanographer interpretation for the proposed methodology are presented in Fig. 4, as we can see the grade "poor" reached the value $7 \%$ demonstrating the robustness of the proposed methodology in term of over or missing-detection. For the "Good" and "Excellent" values of $46 \%$ and $31 \%$ are achieved. Overall, $77 \%$ were reached by the two grades "Good" and "Excellent" together. The mark attributed to the images in Fig. 4 is "Excellent".

After this evaluation of the proposed methodology, over this representative database, we can conclude that the proposed algorithm has provided satisfactory and promessing results.

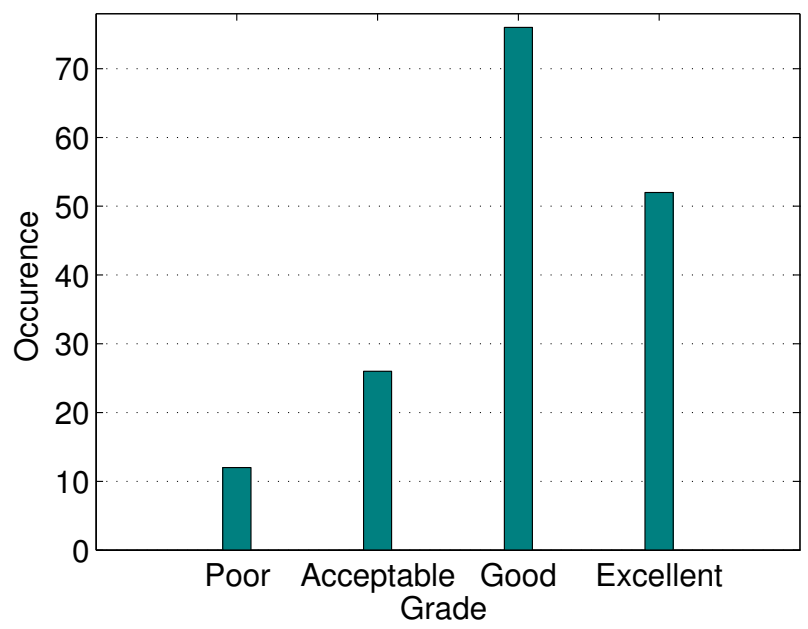

Fig. 5: Qualitative evaluation made by the oceanographer of the $166 \mathrm{chl}-\mathrm{a}$ images for the proposed methodology

\section{CONCLUSIONS AND FUTURE WORK}

In this paper we have presented an automatic tool to deal with the problem of precise segmentation of Moroccan coastal upwelling using satellite chlorophyll images. The proposed methodology starts by the application of Fuzzy Clustering algorithm, that generate labeled image with homogeneous groups of pixels. Then, the algorithm use the region-growing process in order to eliminate isolated components, in offshore waters, not belonging to the upwelling structure.

The proposed methodology have been evaluated and validated by an oceanographer over 166 chlorophyll images during the years 2007 to 2012 covering the coastal ocean of Morocco, The latter has demonstrated a great performance and its ability to automatically extract the upwelling area from the moroccan atlantic coast. Our future work will consist in using this methodology to a combined satellite data products, such as the remotely sensed sea surface temperature and wind speed and direction data. Another goal is to process a much larger database in order to validate and improve the effectiveness of our method for detecting the upwelling area.

\section{ACKNOWLEDGEMENT}

This work is funded by the French-Morrocan research program Toubkal/16/ 24.

\section{REFERENCES}

[1] Chlorophyll concentration (1 month - aqua/modis). http://neo.sci.gsfc. nasa.gov/view.php?datasetId=MY1DMM_CHLORA.

[2] Andrew Bakun. Fronts and eddies as key structures in the habitat of marine fish larvae: opportunity, adaptive response and competitive advantage. Scientia Marina, 70(S2):105-122, 2006.

[3] Jean-Francois Cayula and Peter Cornillon. Edge detection algorithm for sst images. Journal of Atmospheric and Oceanic Technology, 9(1):6780, 1992

[4] Yian-Leng Chang and Xiaobo Li. Adaptive image region-growing. Image Processing, IEEE Transactions on, 3(6):868-872, 1994.

[5] Emmanuel Chassot, Sylvain Bonhommeau, Gabriel Reygondeau, Karen Nieto, Jeffrey J Polovina, Martin Huret, Nicholas K Dulvy, and Herve Demarcq. Satellite remote sensing for an ecosystem approach to fisheries management. ICES Journal of Marine Science: Journal du Conseil, 68(4):651-666, 2011.

[6] Swapnil Chaudhari, Ramprasad Balasubramanian, and Avijit Gangopadhyay. Upwelling detection in avhrr sea surface temperature (sst) images using neural-network framework. In Geoscience and Remote Sensing Symposium, 2008. IGARSS 2008. IEEE International, volume 4, pages IV-926. IEEE, 2008.

[7] Annalisa Griffa, AD Kirwan Jr, Arthur J Mariano, Tamay Özgökmen, and $\mathrm{H}$ Thomas Rossby. Lagrangian analysis and prediction of coastal and ocean dynamics. Cambridge University Press, 2007.

[8] Javier Marcello, Ferran Marqués, and Francisco Eugenio. Automatic tool for the precise detection of upwelling and filaments in remote sensing imagery. Geoscience and Remote Sensing, IEEE Transactions on, 43(7):1605-1616, 2005.

[9] Susana Nascimento, Pedro Franco, Fátima Sousa, Joaquim Dias, and Filipe Neves. Automated computational delimitation of sst upwelling areas using fuzzy clustering. Computers \& Geosciences, 43:207-216, 2012.

[10] K Nieto, Hervé Demarcq, and S McClatchie. Mesoscale frontal structures in the canary upwelling system: New front and filament detection algorithms applied to spatial and temporal patterns. Remote Sensing of Environment, 123:339-346, 2012.

[11] Theo Pavlidis and Yuh-Tay Liow. Integrating region growing and edge detection. Pattern Analysis and Machine Intelligence, IEEE Transactions on, 12(3):225-233, 1990.

[12] Fatima M Sousa, Susana Nascimento, Hugo Casimiro, and Dmitri Boutov. Identification of upwelling areas on sea surface temperature images using fuzzy clustering. Remote Sensing of Environment, 112(6):2817-2823, 2008.

[13] Ayoub Tamim, Khalid Minaoui, Khalid Daoudi, Abderrahman Atillah, and Driss Aboutajdine. On detectability of moroccan coastal upwelling in sea surface temperature satellite images. In Advances in Visual Computing, pages 386-395. Springer, 2014.

[14] Ayoub Tamim, Khalid Minaoui, Khalid Daoudi, Hussein Yahia, Abderrahman Atillah, and Driss Aboutajdine. An efficient tool for automatic delimitation of moroccan coastal upwelling using sst images. Geoscience and Remote Sensing Letters, IEEE, 12(4):875-879, 2015.

[15] Ayoub Tamim, Khalid Minaoui, Khalid Daoudi, Hussein Yahia, Abderrahman Atillah, Mohammed Faouzi Smiej, and Driss Aboutajdine. A simple and efficient approach for coarse segmentation of moroccan coastal upwelling. In Signal Processing Conference (EUSIPCO), 2013 Proceedings of the 21st European, pages 1-5. IEEE, 2013. 